\title{
Analysis of Tropical Fruit Waste Biomass Generation in Indonesia and Its Reuse Potential
}

\author{
A Brunerová ${ }^{1 *}$ U Hasanudin ${ }^{2}$ D A Iryani ${ }^{3}$ D Herák ${ }^{4}$ \\ ${ }^{I}$ Department of Material Science and Manufacturing Technology, Czech University of Life Sciences Prague, Kamýcká \\ 129, CZ 16500 Prague, Czech Republic \\ ${ }^{2}$ Department of Agro-industrial Technology, Universitas Lampung, Jl. S. Brojonegoro No. 1, Bandar Lampung, \\ Indonesia \\ ${ }^{3}$ Department of Chemical Engineering, Universitas Lampung, Jl. S. Brojonegoro No. 1, Bandar Lampung, Indonesia \\ ${ }^{4}$ Department of Mechanical Engineering, Czech University of Life Sciences Prague, Kamýcká 129, CZ 16500 Prague, \\ Czech Republic \\ *Corresponding author. Email: brunerova@tf.czu.cz
}

\begin{abstract}
Several The following research focuses on analysing waste biomass generated thru the processing of specific tropical fruits, such as Dragon fruit, Duku, Mangosteen, and Snake fruit. The amount (in \%) of produced fruit waste biomass (skin, peel) during fruit processing was monitored, and collected waste biomass was subjected to determination of its basic chemical parameters and elementary composition within its possible utilization as a source of renewable energy. Averaged determined ratio of generated waste biomass of total fruit mass was following: Dragon fruit - 35.83\%, Duku - 23.48\%, Mangosteen - 69.40\% and Snake fruit - 15.16\%.Analysis of moisture content Mc(\%) exhibited unwanted high values of such indicator (44.57 - 61.70\%), but satisfactory level of ash content $A c(1.15-8.23 \%)$, which indicated suitability for combustion purposes. Observed $M c$ results may be improved byusing solar renewable energy. Elementary composition analysis proved a suitable ratio of $C: N( \pm 25-30: 1)$ in the case of Dragon fruit and Duku fruit samples, which indicated their suitability as a natural fertilizer in the form of the compost.In conclusion, investigated specific fruit waste biomass contributes to the waste production in a significant way. Therefore, their sustainable utilization is necessary and due to the observed data also advantageous (possible highly advanced source of green energy purposes.
\end{abstract}

Keywords: waste biomass, elementary composition, compost

\section{INTRODUCTION}

Agricultural Waste biomass represents all organic waste materials originating from plants, bacteria, cyanobacteria, fungi, as well as from animals. Various kinds of waste biomass originated from agriculture sector, mainly from processing of agriculture crops. Majority of such waste biomass materials can be recycled or reused as a feedstock for production of alternative environmentally friendly biofuels (in liquid, solid or gaseous form) [1]. Mentioned biofuels are offering new possibilities how to ensure the energy demand nowadays and conserve environment at the same time.

Unfortunately, worldwide energy consumption is still ensured by the fossil fuels, whose using causes serious environmental damages; specifically, $31 \%$ of produced energy originated from oil, $29 \%$ from coal, $21.2 \%$ from natural gas and only $10.3 \%$ from waste biomass-based biofuels in 2014 , despite the fact that waste biomass has a great potential in energy production sector. The advantage of waste biomass lies in its low carbon and greenhouse gas emissions and mainly in its availability [2, 3].

The oil represents a primary energy source in Indonesia, specifically, a 1.61 billion barrel oil equivalent (BOE) was monitored in 2013.Nevertheless, utilization of waste biomass in its raw unprocessed form (firewood, empty coconut shells or empty fruit bunches) is still common in many regions in Indonesia, thus, the habit of waste biomass utilization is still between the wide public mostly in rural areas. Nevertheless, the amount of energy generated by biofuels achieved only 4\% in 2013 in Indonesia [4]. 
Dragon fruit, also known as a Pitaya, Pitahaya or Strawberry Pear grows on the climbing cactus plant and currently is cultivated in countries like of Southeast Asia, Israel, Australia, China, Philippines, Hawaii, Mexico, Colombia or Spanish. Duku fruit is commonly also called Doekoe or Dookoo and grows on robust tree in Southeast Asia, in Hawaii, Surinam or Rica. Mangosteen fruit, also called Mang-khud or Manggis, grows on the slow-growing tree in Southeast Asia. Finally, Snake fruit, also called Salak or Buahular, grows at short-stemmed palm in Southeast Asia [5-9].

Abundant amount of fruit waste biomass is generated worldwide within the food processing processes. Unfortunately, its subsequent utilization or recycling in not the matter of course; in many cases is such fruit waste biomass left behind without any useful reuse. The impact of such bad waste management can be reduced by reusing of specific parts of the fruit waste biomass (bioactive components converting) for production of biofuels $[10,11]$.

The main aim of present investigation was to analyse the amount of waste biomass (\%) of selected tropical fruit kinds (Dragon fruit (Hylocereus Polyrhizus), Duku (Lansium Domesticum Correa), Mangosteen (Garcinia mangostana L.) and Snake fruit (Salaccazalacca) generated during the fruit processing (skinning, peeling). Further, the chemical analysis of generated fruit waste biomass was also the subject of the investigation within the statement of such waste materials potential sustainable reuse or recycling.

\section{MATERIALS AND METHODS}

Materials and samples used in performed investigation originated from Bandar Lampung, Lampung district, Sumatra, Republic of Indonesia (see Figure 1) and represent fruit waste biomass generated during fruit processing.

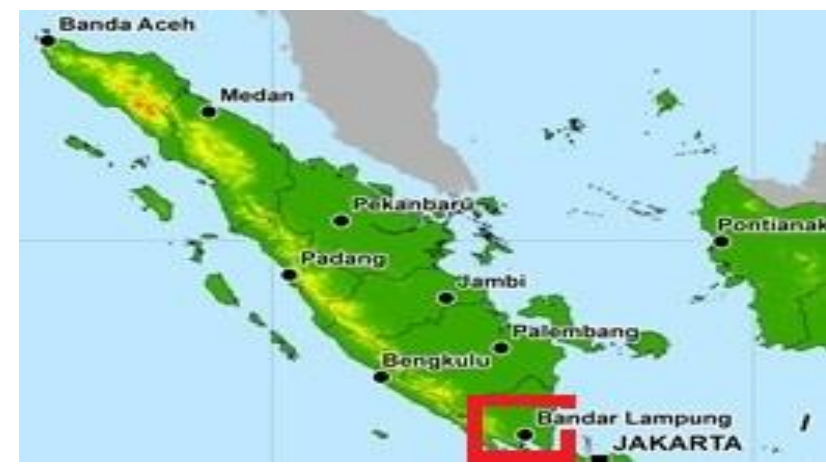

Figure1 Target place of investigated samples growth, processing and collection

Specifically, the fruit components as an exocarp, mesocarp, endocarp (outer skins, peels) of Dragon fruit, Duku fruit, Mangosteen fruit and Snake fruit. Table 1 describes taxonomical origin of selected fruit.

Table 1. Taxonomical characterization of investigated fruit kinds

\begin{tabular}{|l|l|l|l|}
\hline \multicolumn{1}{|c|}{ Fruit } & \multicolumn{1}{|c|}{ Latin name } & \multicolumn{1}{c|}{ Family } & \multicolumn{1}{c|}{ Origin } \\
\hline Dragon fruit & HylocereusPolyrhizus & Cactaceae & Central America \\
\hline Duku & LansiumDomesticumCorrea & Meliaceae & Western Malaysia \\
\hline Mangosteen & Garcinia mangostana L. & Guttiferae & Sunda and Maluku islands \\
\hline Snake fruit & Salaccazalacca & Arecaceae & Southwest Java, South Sumatra \\
\hline
\end{tabular}

All samples were collected during rainy season from February to May 2019 within the local markets or small processing plants in Bandar Lampung. Investigated fruit kinds were chosen because they represent popular, wellknown and widely consumed agriculture crops in
Indonesia, thus, the generation of fruit waste biomass during their processing was ensured. The form of collected fruit waste biomass sample sis expressed in Figure 2 below. 


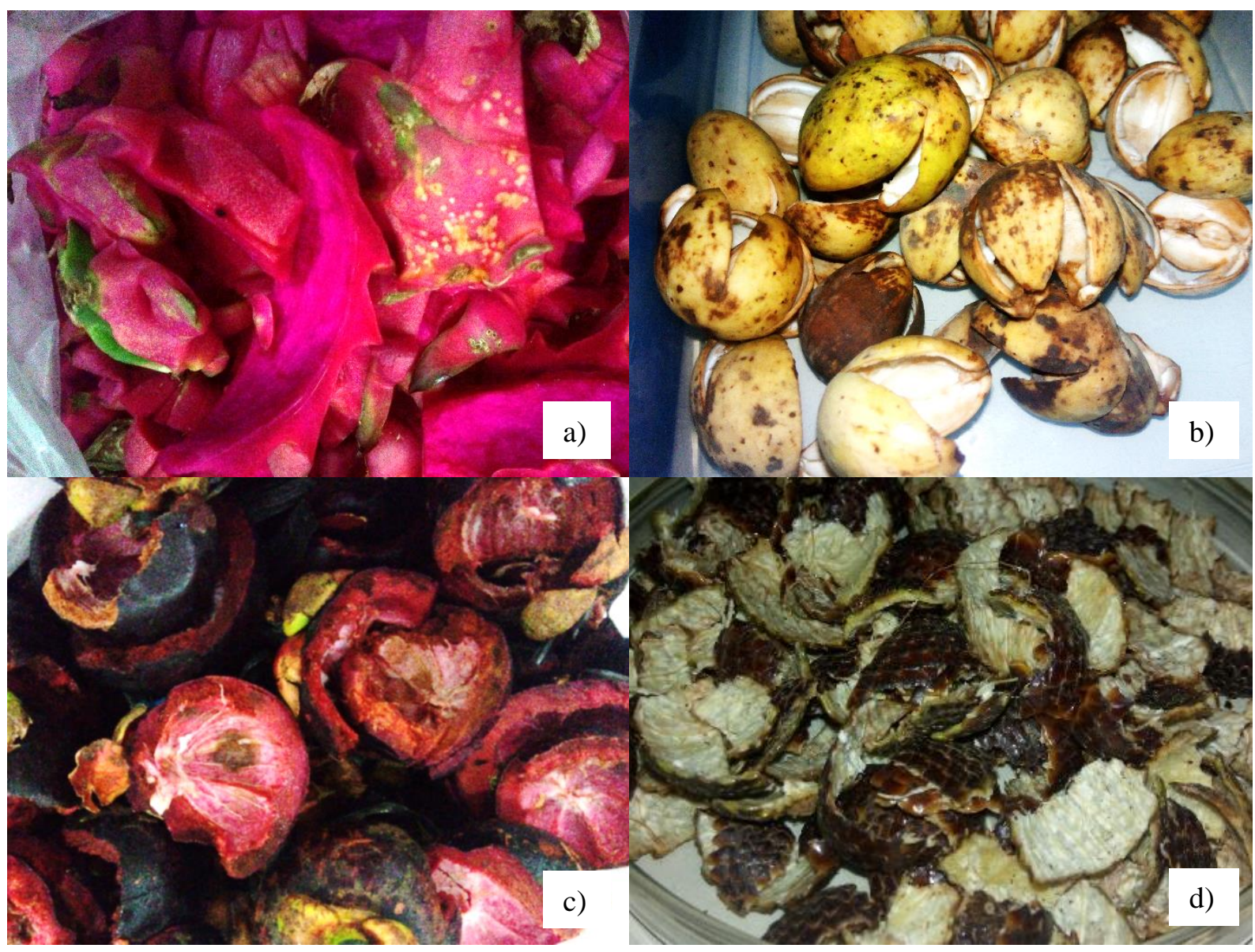

Figure 2 Investigated samples (skins, peels) before experimental measurements: a) Dragon fruit, b) Duku fruit, c) Mangosteen fruit, d) Snake fruit

First monitored parameter was the amount (in \%) of waste biomass of total fruit mass generated during fruits processing. Experimental measurement was following; each of fruit sample was independently weighted before processing (skinning, peeling) and after processing, as well as the generated waste biomass was weighted. Observed data were subsequently used for calculation of percentage of waste biomass generated of total fruit mass by using of following formula (see Equation 1):

$$
F W B=\frac{m_{2}}{m_{1}} \cdot 100
$$

$m_{1}$ - mass of fruit before processing $(\mathrm{g})$,

$m_{2}$ - mass of fruit after processing,

$F W B$ - amount of fruit waste biomass (\%)
Subsequently, a chemical analysis of collected fruit biomass samples was performed within the statement of its possible subsequent utilization as a source of renewable energy. Determination of fuel parameters contained of determination of moisture content $M c(\%)$, ash content $A c(\%)$, total solids $T S(\%)$, volatile solids VS (\%) and of elementary composition as a Carbon $C$ (\%), Nitrogen $N(\%)$ and Hydrogen $H(\%)$. All experiments were performed directly after the samples collection and were conducted to mandatory technical standards related to the determination of biomass parameters and its utilization for direct combustion processes; namely, to Standards EN ISO 16948 (2016), EN ISO 18123 (2016), ISO 18122 (2015), EN 18134-2 (2015). Determination of moisture content $M c(\%)$ was performed by using of laboratory oven Memmert, type UN55 (Schwabach, Germany); the investigated samples 
were dried for 24 hours at $102^{\circ} \mathrm{C}$ until their constant weight. Determination of Ac (\%), total solids TS (\%) and volatile solids $V S(\%)$ was performed by using of laboratory muffle furnace oven ISUZU, type EPTR-13K (Sanjo, Japan); the investigated samples were dried for 6 hours at $600^{\circ} \mathrm{C}$ until the weight of ash was constant.

\section{RESULTS AND DISCUSSION}

Main objective of performed research was to analyse the amount of fruit waste biomass (\%) generated during the specific fruit kinds processing (skinning, peeling). Detail data of such observation are noted in Table 2 below.

Table 2. Waste biomass analysis of investigated fruit kinds

\begin{tabular}{|l|c|c|c|c|}
\hline \multirow{2}{*}{ Sample } & $m_{1}$ & $m_{2}$ & $m_{w}$ & $F W B$ \\
\cline { 2 - 5 } & $(\mathrm{g})$ & $(\mathrm{g})$ & $(\mathrm{g})$ & $(\%)$ \\
\hline Dragon fruit & $588.95 \pm 120.50$ & $381.43 \pm 98.17$ & $207.52 \pm 37.63$ & $35.83 \pm 5.75$ \\
\hline Duku & $17.78 \pm 4.30$ & $13.68 \pm 3.75$ & $4.20 \pm 0.77$ & $23.48 \pm 5.14$ \\
\hline Mangosteen & $89.24 \pm 27.39$ & $28.03 \pm 12.31$ & $61.21 \pm 17.72$ & $69.40 \pm 9.04$ \\
\hline Snake fruit & $74.10 \pm 8.94$ & $62.88 \pm 7.85$ & $11.22 \pm 1.77$ & $15.16 \pm 1.78$ \\
\hline
\end{tabular}

$m_{1}$ - mass of fruit before processing, $m_{2}$ - mass of fruit after processing $(\mathrm{g}), m_{w^{-}}$mass of generated waste biomass,

$F W B$ - amount of fruit waste biomass, \pm - standard deviation

As is visible, the greatest amount of fruit waste biomass was proved in case of Mangosteen fruit $(69.40 \%)$, while lowest ratio of waste biomass to fruit was monitored in Snake fruit case (15.16\%). Nevertheless, the amount of generated fruit waste biomass of all investigated fruit kinds occurred at high level, thus, production of great amount of waste biomass material within such fruit products and by-products production can be indicated. In consequence, subsequent utilization for some of the environmentally friendly purpose should be highly supported.

Laboratory experimental measurements focused on the basic chemical parameters of obtained fruit waste biomass (see Table 3) primarily expressed the level of moisture content $M c(\%)$. As was expected, the level of moisture content $M c(\%)$ occurred at high level in case of all investigated fruit waste biomass samples, which is directly related to the taxonomical origin of fruit kinds. Obtained result can be considered as a limitation within subsequent reuse of such waste materials, due to the fact, that its conversion into the biofuels or its components commonly contain of drying process, which represent an energy investment. Nevertheless, countries as an Indonesia dispose of great potential of solar drying sustainable technologies (renewable source of energy), which can be easily applied and can solve the energy demand issue.

Table 3. Chemical parameters and energetic potential of investigated fruit biomass samples

\begin{tabular}{|l|c|c|c|c|}
\hline Sample & $\begin{array}{c}\text { MC } \\
(\%)\end{array}$ & $\begin{array}{c}\text { AC } \\
(\%)\end{array}$ & $\begin{array}{c}\text { TS } \\
(\%)\end{array}$ & $\begin{array}{c}\text { VS } \\
\text { (\%) }\end{array}$ \\
\hline Dragon fruit & $61.70 \pm 0.98$ & $1.36 \pm 0.04$ & $38.30 \pm 0.98$ & $36.94 \pm 1.02$ \\
\hline Duku & $74.64 \pm 0.46$ & $1.89 \pm 0.02$ & $25.36 \pm 0.46$ & $23.47 \pm 0.44$ \\
\hline Mangosteen & $59.45 \pm 0.29$ & $8.23 \pm 0.22$ & $40.55 \pm 0.29$ & $32.32 \pm 0.19$ \\
\hline Snake fruit & $44.57 \pm 0.06$ & $1.15 \pm 0.05$ & $55.43 \pm 0.06$ & $54.28 \pm 0.01$ \\
\hline
\end{tabular}

$M c$ - moisture content, $A c$ - ash content, $T S$ - total solids, $V S$ - volatile solids, $C V$ - calorific value, \pm - standard deviation

Analysis of ash content $A c(\%)$ proved satisfactory level of such chemical quality indicator in case of all investigated samples. Great results (comparable with wood biomass) were achieved by samples of Dragon fruit, Duku fruit and Snake fruit; the results of Mangosteen fruit occurred at higher level, but it is still acceptable result. Such observation proved that investigated fruit waste biomass samples are suitable for process of direct combustion, which indicated that they can be used as a feedstock material for production of solid biofuels like bio-briquettes or bio-pellets. 
Finally, the elementary composition of samples was performed in effort to state their suitability for recycling purposes, specifically, to be used as a natural fertilizer in the form of the compost. For production of high quality compost the proper Carbon-Nitrogen ratio must be achieved, approximately 25-30:1 (C:N). Regarding to observed data, expressed in Table 4, the proper ratio of $C: N$ was observed in case of Dragon fruit and Duku Fruit samples. In case of Mangosteen and Snake fruit the ratio of $C: N$ was too high (excess of Carbon), which would in practice results in unrequired slow decomposition of compost components.

Table 4. Elementary composition of investigated fruit biomass samples

\begin{tabular}{|c|c|c|c|}
\hline Sample & $\begin{array}{l}N \\
(\%)\end{array}$ & $\begin{array}{c}C \\
(\%)\end{array}$ & $\begin{array}{l}H \\
(\%)\end{array}$ \\
\hline Dragon fruit & $1.76 \pm 0.02$ & $37.23 \pm 0.49$ & $5.33 \pm 0.04$ \\
\hline Duku & $1.57 \pm 0.06$ & $50.63 \pm 0.15$ & $7.24 \pm 0.09$ \\
\hline Mangosteen & $0.69 \pm 0.04$ & $49.98 \pm 1.70$ & $6.14 \pm 0.23$ \\
\hline Snake fruit & $0.88 \pm 0.02$ & $46.08 \pm 0.06$ & $6.23 \pm 0.06$ \\
\hline
\end{tabular}

$N$ - Nitrogen, $C$ - Carbon, $H$ - Hydrogen, \pm - standard deviation

\section{CONCLUSION}

In conclusion, performed research proved production of great amount of fruit waste biomass from processing of investigated tropical fruit kinds, while greatest amount of waste biomass was monitored in case of Mangosteen and Dragon fruit, specifically, $69.40 \%$ and $35.83 \%$ of total raw fruit mass (in order). Thus, subsequent reuse of such waste materials within specific environmentally friendly purposes was highly recommended. Chemical analysis proved undesirable high level of moisture content in case of all samples, but it can be easily improved by using of solar energy. Moreover, determination of ash content expressed extremely good result values (comparable with wood biomass), which proved the suitability of samples for processes of direct combustion (solid biofuel production). Elementary composition proved the efficiency and advantage of Dragon fruit and Duku fruit waste biomass in production of natural fertilizer, while they proved their suitability within being a suitable component of high-quality compost. In the end, It is important to realize and understand the fact that such fruit waste biomass materials are produced every day in great amount and they do not represent useless waste, but commodity with high potential, which can be valorised, reused or convert into specific type of biofuel or fertilizer. In all cases should be treated according to the sustainable steps of proper waste management.

\section{ACKNOWLEDGMENT}

The performed research was primarily funded by the EUROPEAN UNION (EU), managing authority of the Czech Operational Programme Research, Development and Education within the project "Supporting the development of international mobility of research staff at CULS Prague", reg. no. CZ.02.2.69/0.0/0.0/16_027/0008366. Further, research was supported by the Internal Grant Agency of the Czech University Life Sciences Prague, grant number 20173005 (31140/1313/3108) and by Internal Grant Agency of the Faculty of Engineering, Czech University of Life Sciences Prague, grant number 2019:31140/1312/3103. 


\section{REFERENCES}

[1] Sarkar N, Ghosh SK, Bannerjee S and Aikat K 2012 Bioethanol production from agricultural wastes: An overview. Renew. Energ.37(1): 1927.

[2] Naik SN, Goud VV, Rout PK and Dalai AK 2010. Production of first and second generation biofuels: a comprehensive review.Renew. Sust. Energ Rev.14(2): 578-597.

[3] Samal AP, Patel SK and Kumar M 2016 Characterization of properties and estimation of power generation potentials of some woody biomass residues, Energy Sources, Part A Recovery.Util. Environ. Eff.38(12): 1819-1824.

[4] Ministry of Energy and Mineral Resources of Indonesia 2015.Handbook of Energy and Economic Statistics of Indonesia. Ministry of Energy and Mineral Resources of Indonesia, Jakarta Indonesia.[Online] Accessed on $1^{\text {st }}$ March 2020 Available from:

[8] Vinay GM, Sakthivel T and Priyanka HL 2017 Recent Advances in Annona Breeding: A Review. Int. J. Pure App. Biosci.5(2):11681181http://dx.doi.org/10.18782/2320-7051.2722

[9] Jirovetz L, Buchbauer G and Ngassoum M B 1998 Essential Oil Compounds of the Annona muricata Fresh Fruit Pulp from Cameroon. J. Agric. Food Chem.46(9): 3719-3720. DOI: http://dx.doi.org/10.1021/jf980204n https://www.esdm.go.id/assets/media/content/con tent-handbook-of-energy-and-economicstatistics-of-indonesia-2018-final-edition.pdf

[5] Supriyadi, Suhardi, Suzuki M, Yoshida K, Muto T, Fujita A and Watanabe N 2002 Changes in the volatile compounds and in the chemical and physical properties of snake fruit (SalaccaedulisReinw) Cv. Pondoh during maturation J. Agric. Food Chem.50(26):76277633

DOI: http://dx.doi.org/10.1021/jf020620e

[6] Blancke R 2016 Tropical fruits and other edible plants of the world.An illustrated guide. New York: Comstock Publishing AssociatesISBN: 9780801454172.

[7] Morton J F. 1987 Strawberry Pear.Fruits of warm climates. Miami: Julia F. Morton, FL. 33189ISBN: 0-9610184-1-0

[10] Nanda S, Isen J, Dalai A K, Dalai A K and Kozinski J A 2016Gasification of fruit wastes and agro-food residues in supercritical water. Ener. Conver. and Manag.110: 296-306. DOI: http://dx.doi.org/10.1016/j.enconman.2015.11.06 0

[11] McKendryP 2002 Energy production from biomass (part 1): overview of biomass.Biores. Technol.83:

37-46. 